\title{
INDRA - Climate Resilience Platform for the City of Makassar
}

\author{
$\underline{\text { V. C. N. Weeraratne }}^{a}{ }^{(D,}$, M. Prakash ${ }^{a}$, R. C. Z. Cohen a ${ }^{(D)}$ and N. Garg ${ }^{a}$ \\ ${ }^{a}$ CSIRO Data61, Clayton, Victoria, Australia \\ Email: Vihan.Weeraratne@,csiro.au
}

\begin{abstract}
INDRA (https://research.csiro.au/indra) is a web-based climate and hazard risk analytics and visualisation platform developed by CSIRO Data61 to solve the challenges associated with present day climate and future climate change related datasets. These challenges include accessibility of datasets and the interoperability with other datasets such as demographics and infrastructure. INDRA Makassar was developed to solve these challenges for the City of Makassar in the province of South Sulawesi in Indonesia, thereby developing a climate resilience framework for the rapidly growing region. The INDRA platform is currently being expanded to reach out to a broad range of stakeholders in Australia first and globally thereafter. The INDRA platform for Makassar was supported by the Asian Development Bank as a part of the ASEAN Australia Smart Cities Trust Fund (AASCTF). It was developed with inputs from Ramboll and the University of Hasanuddin in Makassar. A comprehensive collection of climate, demographic, infrastructure, and region/place datasets were presented on INDRA Makassar as easily mappable and downloadable layers. Several climate and hazard datasets across different spatio-temporal scales were deployed to help decisionmakers easily understand risks and social vulnerability involved with climate change. These layers included sea-level rise inundation layers, projected climate layers such as temperature and precipitation, historical climate layers, current and projected population layers and land-use layers. Infrastructure layers included roads, drainage networks and hospitals.

The already modelled climate projections and historical climate data for maximum temperature, precipitation and minimum temperature were derived from the WorldClim v2.1 dataset (Eyring et al., 2016; Fick and Hijmans, 2017). The sea level rise inundation layers were bathtub fill (modelling) layers resulting from imposing sea-level rise values to current high tide levels for South Sulawesi and provided a good understanding of high-risk areas for different sea-level rise scenarios expected in the future. The modelling of inundation layers involved a detailed literature study and utilised the best available terrain and bathymetric data for the region. Furthermore, multiple datasets can be combined and viewed to better understand challenges that the region may face in the future. For example, the predicted population layer can be combined with any of the climate layers to better understand communities at risk. The INDRA framework will help urban planners to make the City of Makassar future-proof by making the city more resilient to climate change by providing easily accessible climate information on multiple time scales including historical data and future climate projections.
\end{abstract}

Keywords: Climate change, climate data, climate resilience, urban risk analysis, sea-level rise 


\section{INTRODUCTION}

As a part of the ASEAN Australia Smart Cities Trust Fund (AASCTF), the Asian Development Bank (ADB), Ramboll and other Indonesian agencies approached CSIRO Data61 to develop a digital climate risk resilience platform for Makassar, a region in the Indonesian province of South Sulawesi (Figure 1). The purpose of this project was to provide modelled climate change-related datasets together with additional datasets to relevant parties in an easily accessible platform. The platform helps decision-makers assess risks and social vulnerability whilst planning the rapidly growing city to be more resilient to the impacts of climate change.

INDRA is a Climate and Hazard Risk Analytics and Visualisation Platform developed by CSIRO Data61 which integrates a range of datasets including climate, natural hazards, infrastructure and demographics. Accessing, interpreting and using climate data has been very challenging for many end-users. The platform supports local governments, urban planners, and other interested parties in planning and to understand and develop climate adaptations for vulnerable regions, the broader INDRA platform is being developed so that it can serve the needs in Australia, the Indo Pacific region next and Globally thereafter. INDRA was used in developing the platform for Makassar by incorporating datasets from the core INDRA framework, custom datasets generated for this particular project and datasets provided by external parties including Ramboll. The climate and hazards data included climate projections and historical climate data for maximum temperature, precipitation and minimum temperature which were derived from the WorldClim v2.1 dataset (Eyring et al., 2016; Fick and Hijmans, 2017). Sea-level rise inundation layers were bathtub fill (modelling) layers resulting from imposing sea-level rise values to current high-tide levels for South Sulawesi and provides a good understanding of high-risk areas for different sea-level rise scenarios expected in the future.

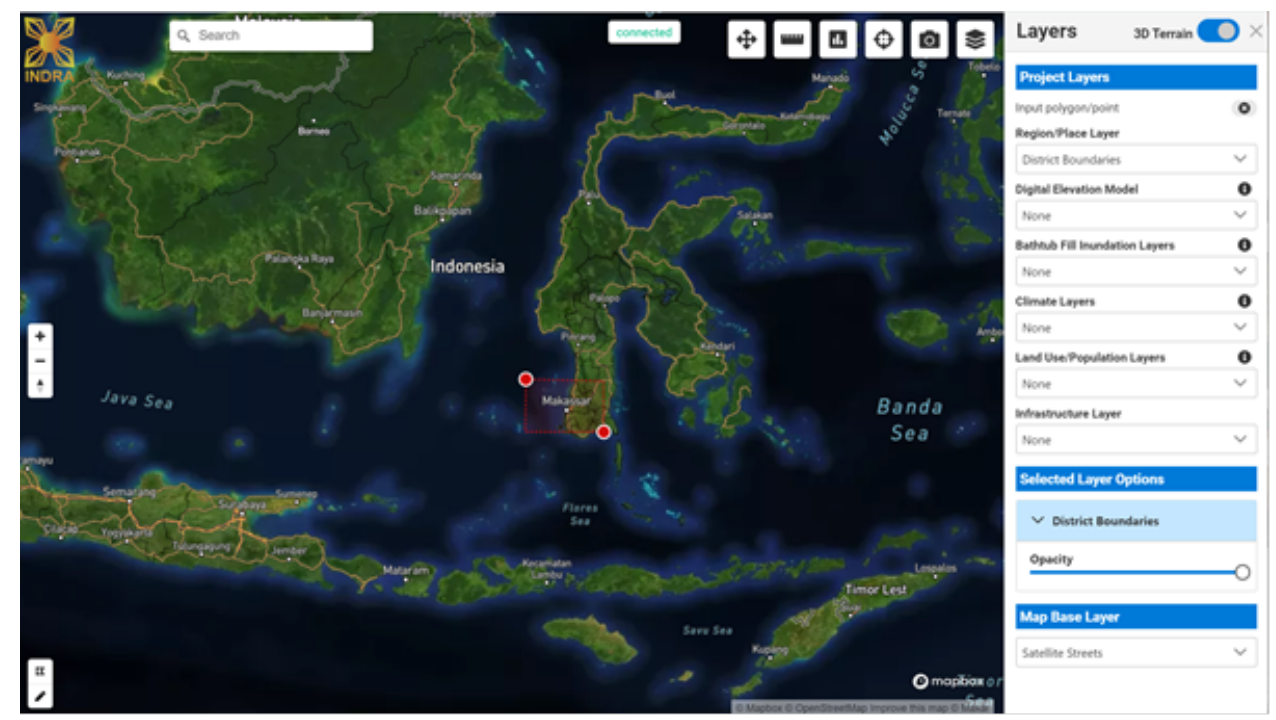

Figure 1. Location of Makassar in Indonesia (area highlighted in red)

\section{INDRA MAKASSAR PLATFORM}

A custom version of INDRA was developed for this project focused on the region of Makassar, this INDRA version was called "INDRA Makassar" and contained a variety of curated datasets relevant for the region. These datasets are discussed in more detail in the next section. The platform is a web application which is accessed through the end user's web browser. The more hardware intensive processes were done on the server-side, therefore, the computer hardware requirements for an end-user are very minimal, the most important requirement being a stable internet connection. This ensures ease of accessibility to the platform for anyone, from anywhere in the world solving one of the main challenges that is faced today by relevant authorities.

\subsection{User interface}

The user interface was designed in a way that enables any stakeholder at any skill level to navigate and get a meaningful understanding of the climate risks and hazards relevant to a region. Figure 1 highlights the main user interface for the platform, with the menu panel on the right-hand side of the application. The application centres to Makassar upon initialisation. The displayed basemap is fetched from Mapbox and the "Light" basemap is chosen by default. Alternative basemaps which include "Dark", "Satellite" and "Satellite Streets" 
can be selected from the dropdown list on the right. Additionally, the map can be viewed in 3D by toggling the "3D Terrain" button. The panel on the right contains all the map layer groups included in the project. These layer groups consist of multiple layers that can be turned on depending on the user's preference. The layer groups included on INDRA Makassar were, Region/Place Layers, Digital Elevation Model (DEM), Bathtub Fill Inundation Layers, Climate Layers, Land Use/Population Layers and Infrastructure Layers.

\subsection{Platform hosting and access}

Currently, the platform is hosted on Microsoft Azure. The application is built on an Azure Virtual Machine (VM) with 4 vCPUs, 16 GB of RAM and $32 \mathrm{~GB}$ of disk space. The platform is accessed via the URL https://makassar.indraweb.io to authorised users. Currently, access has been granted to specific officers and researchers at Ramboll and in Universities in Makassar.

\section{INDRA MAKASSAR DATASETS AND LAYERS}

Climate datasets are extremely valuable information that governments and other planning authorities are keen on acquiring due to the critical guidance that these data provide in planning cities whilst accommodating for climate change-related adaptations. However, these datasets are not easily accessible because they are generally available in complicated scientific formats. The INDRA platform addresses this issue by presenting climate datasets in an all-inclusive and easy to view web-based system. The datasets are processed on the backend and presented as selectable layers on the INDRA user interface. Furthermore, some datasets are used in climate and flood modelling to produce important outputs that are presented on the platform. The climate layers can be downloaded easily in any of the most common geospatial data formats.

\section{CORE INDRA LAYERS}

The core INDRA layers are the layers which are available via most INDRA implementations as a standard feature and are also included in INDRA Makassar as key local information. These layers included historical and modelled future climate projections (CMIP6) for the region based on WorldClim v2.1 data (Eyring et al., 2016; Fick and Hijmans, 2017). The benefit of presenting these datasets on INDRA was the ease of accessibility that is provided for stakeholders of all skill levels. Climate datasets such as these are generally available in rather complicated scientific formats which are not easily accessible. INDRA brings in these datasets and allows the user to select the necessary parameters on a simple interface and download the relevant data with a click of a button. The complicated process of fetching the data was handled on the server-side with the use of a python backend utilising the server's resources. The two types of climate layers are explained in detail in the following sections.

\subsection{Projected climate}

The CMIP6 projected climate layers were already modelled data downscaled by Fick and Hijmans (2017) and were presented at a spatial resolution of $4.5 \mathrm{~km}$. In the INDRA user interface, multiple parameters can be selected to display any of the projected climate layers available. The displayed layer can be downloaded in any of the 3 commonly used geospatial formats using the relevant button; "TIFF" (GeoTIFF), "Shape" (shapefile) and "JSON" (GeoJSON). The selectable parameters are discussed below.

\section{Climate variable}

The available climate projected climate variables were maximum temperature, precipitation and minimum temperature available at monthly and annual frequencies as described in the subsequent sections.

\section{Shared socioeconomic pathways (SSP)}

Different narratives which describe distinct socioeconomic trends going into the future. The severity of climate impacts varies according to the narrative (Hausfather, 2019). Two SSP's were presented on INDRA. SSP245 describes a medium emissions scenario where historical patterns of development are continued. The second SSP scenario is the SSP585 which is a high emissions condition and the worst-case-scenario for negative climate impacts with energy-intensive rapid development alongside abundant fossil fuel use.

\section{Global climate models (GCMs)}

The GCMs included on this platform were the results of the two climate modelling groups MIROC (an ensemble of Japanese research institutions) and MRI (Meteorological Research Institute, Tsukuba) which are both based in Japan. The three available GCM options are, MIROC-E2SL, MIROC6 and MRI-ESM2-0. 


\section{Frequency}

The data can be viewed at an annual or monthly temporal resolution (frequency). Projections for each month can be viewed if the monthly projection is selected. For the annual frequency, the expected annual climate projections were displayed for the selected "Projected Year Range".

\section{Timeslice}

The option is visible once the "Monthly" option is selected under the Frequency option. Any of the twelve months in a year can be selected to view the projected data for that month.

\section{Projected year range}

Four selections for year ranges are available which averages 20-year periods; 2021-2040, 2041-2060, 20612080 and 2081-2100.

\subsection{Historical Climate}

Historical layers included on the platform represent climate variables such as precipitation and temperature condensed into annual and monthly timescales. The layers can be downloaded in the same geospatial formats as the projected climate layers. The selectable layer options were similar to the projected climate layers as well.

\section{Climate variable}

The available historical climate layers were maximum temperature, precipitation and minimum temperature available at monthly and annual frequencies as described in the subsequent sections.

\section{Frequency}

The data can be viewed at an annual or monthly temporal resolution (frequency). Projections for each month can be viewed if the monthly projection is selected. For the annual frequency, the expected annual climate projections were displayed for the selected "Projected Year Range".

\section{Timeslice}

The option is visible once the "Monthly" option is selected under the Frequency option. Any of the twelve months in a year can be selected to view the data for that month.

\section{Year range}

Historical climate data were made available for the year range 1970-2000.

\section{EXTERNALLY ACQUIRED LAYERS}

Layers added to INDRA Makassar as per specific needs of the project were included under this category. Some datasets were acquired through research and some were provided by external stakeholders including Ramboll and the University of Hasanuddin. Table 1 summarises the externally acquired layers. The Digital Elevation Model (DEM) for the region was one such layer which was a critical dataset as the DEM was used for inundation modelling for understanding the risks associated with sea-level rise. The demographic layers which include the current population, predicted population in 2040 and change in total housing demand between the years 2021-2040 were based on modelling done by Ramboll.

\section{PROJECT SPECIFIC LAYERS}

Layers were created based on already acquired datasets to further assess climate-related risks to the region of Makassar. The sea-level rise inundation layers are a key output of the INDRA Makassar project which assists in identifying high-risk areas in terms of climate change impacts. Furthermore, utilising the SWAT land use data (Table 1), the change in land-use from the year 1996 to 2015 is included.

\subsection{Bathtub fill inundation layers}

A bathtub fill is the most simplistic type of flood model. Bathtub fills consider the underlying terrain (DEM) to fill areas that lie below a certain height threshold. Each cell in the DEM is checked to see if that cell should be flooded depending on the water depth. The layers presented in INDRA were based on the high tide for South Sulawesi which is set as the baseline sea level. An additional height for the baseline sea level was superimposed according to the amount of 'Sea Level Rise' that was chosen. A total of ten sea level rise values from $0.0 \mathrm{~m}$ to $2.0 \mathrm{~m}$ at regular intervals were made available to support stakeholders for undertaking detailed 
inundation risk analyses. It is worth noting that the choice of the DEM greatly affects the bathtub fill flood layers as differences in DEM levels are present. The inundation layers in this project considered the DEMNAS DEM. Furthermore, the ocean was masked out from the inundation data to improve the presentation of results. The inundation layers can be downloaded as geotiffs using the "TIFF" download button. Figure 2 shows an inundation depth layer for a sea-level rise scenario of $0.5 \mathrm{~m}$.

Table 1. Summary of externally acquired layers

\begin{tabular}{|c|c|c|c|}
\hline Layer name & Data type & Source & Additional Information \\
\hline $\begin{array}{l}\text { DEMNAS - } \\
\text { National Digital } \\
\text { Elevation } \\
\text { Model (DEM) } \\
\text { for Indonesia }\end{array}$ & Raster & $\begin{array}{l}\text { Geospatial } \\
\text { Information } \\
\text { Agency } \\
\text { Indonesia, } \\
2018\end{array}$ & $\begin{array}{l}\text { Seamless Digital Elevation Model (DEM) and } \\
\text { National Bathymetry for Indonesia at a spatial } \\
\text { resolution of } 0.27 \text {-arcseconds (approximately } 7.5 \mathrm{~m} \mathrm{x} \\
7.5 \mathrm{~m} \text { ) (Geospatial Information Agency Indonesia, } \\
2018 \text { ). The original data uses the EGM2008 vertical } \\
\text { datum, the vertical datum was converted to EGM96. }\end{array}$ \\
\hline $\begin{array}{l}\text { SWAT Land } \\
\text { Use }\end{array}$ & Raster & $\begin{array}{l}\text { University } \\
\text { of } \\
\text { Hasanuddin }\end{array}$ & $\begin{array}{l}\text { SWAT land use data which was available for two } \\
\text { years; } 1996 \text { and } 2015 \text {. The land use type value } \\
\text { definitions were based on the report by the Texas } \\
\text { A\&M University (2012). }\end{array}$ \\
\hline $\begin{array}{l}\text { Population and } \\
\text { Population } \\
\text { Change }\end{array}$ & $\begin{array}{l}\text { Vector } \\
\text { converted } \\
\text { to Raster }\end{array}$ & Ramboll & $\begin{array}{l}\text { Population in } 2019 \text { and the projected population for } \\
2040 \text { for different regions in Makassar. The } \\
\text { population change layer shows the increase in } \\
\text { population. }\end{array}$ \\
\hline $\begin{array}{l}\text { Total Housing } \\
\text { Demand: } 2021 \\
\text { to } 2040\end{array}$ & $\begin{array}{l}\text { Vector } \\
\text { converted } \\
\text { to Raster }\end{array}$ & Ramboll & $\begin{array}{l}\text { Change in housing demand from the year } 2021 \text { until } \\
\text { the year } 2040 \text {. The data was based on the population } \\
\text { and the average household size for Makassar. }\end{array}$ \\
\hline $\begin{array}{l}\text { Layer Group: } \\
\text { Region/Place } \\
\text { Layers }\end{array}$ & $\begin{array}{l}\text { Collection } \\
\text { of vector } \\
\text { layers }\end{array}$ & $\begin{array}{l}\text { Ramboll and } \\
\text { University } \\
\text { of } \\
\text { Hasanuddin }\end{array}$ & $\begin{array}{l}\text { Some layers included in this layer group; district } \\
\text { boundaries, sub-district boundaries, river basins, } \\
\text { strategic areas, etc. }\end{array}$ \\
\hline $\begin{array}{l}\text { Layer Group: } \\
\text { Infrastructure } \\
\text { Layers }\end{array}$ & $\begin{array}{l}\text { Collection } \\
\text { of vector } \\
\text { layers }\end{array}$ & Ramboll & $\begin{array}{l}\text { Some layers included in this layer group; drainage } \\
\text { networks, roads, railroads, hospitals, education } \\
\text { facilities, etc. }\end{array}$ \\
\hline
\end{tabular}

\section{Initial sea level (at 0 m SLR): baseline sea level of 1.4 m EGM96}

The study, by Alisjahbana et al. (2010) stated that the tidal height in South Sulawesi is about $1.2 \mathrm{~m}$ to $1.4 \mathrm{~m}$ and reaches $1.6 \mathrm{~m}$ to $1.8 \mathrm{~m}$ in North Sulawesi, the lowest tide reaches $-1.4 \mathrm{~m}$ and $-1.8 \mathrm{~m}$ respectively. Additionally, the study by Heliani et al. (2002) summarised mean sea levels in Indonesian waters with respect to the EGM96 vertical datum. According to the 3-month spatial averages given in the study, the sea level is highest in January in the middle of the rainy season and decreases until July in the middle of the dry season. The 3-month average sea level between December 1994 - February 1995 was approximately $1.5 \mathrm{~m}$ with reference to EGM96. The highest tide for South Sulawesi of $1.4 \mathrm{~m}$ is chosen in this exercise.

\section{Sea level rise}

Expected amounts of sea-level rise for Indonesia were discussed in detail in the study by Alisjahbana et al. (2010). In summary, sea-level rise predictions using three main methods were discussed, based on tide gauge readings, based on altimeter ADT and based on climate models. Although these three different methods do not perfectly match up in terms of values, the rise in sea levels over time are correlated. Examples for the most popular and globally accepted climate models are the IPCC AR4 and post-IPCC AR4 models.

\section{IPCC AR4 model sea level rise projections}

A widely accepted climate model in the context of sea-level rise is the IPCC AR4 model. Predicted sea-level rise based on the MRI 3.2 model applied to the IPCC SRESalb scenarios assuming $\mathrm{CO}_{2}$ concentration of 750 ppm for Indonesian waters is $0.7 \mathrm{~cm} /$ year to $0.8 \mathrm{~cm} /$ year. Therefore, relative to the year 2000 level, expected sea-level rise values are presented in Table 2. 
Post-IPCC AR4 sea level rise projections

The IPCC AR4 underestimates the melting of glacial ice and mostly considers the increase of seasurface temperature (SST) $(30 \%$ melting of glacial ice and $70 \%$ for the rise of SST) (Alisjahbana et al., 2010). More recent research suggests that the melting of glacial ice has a more significant role in sea-level rise (feedback loop created by the reduction in ice cover which would trap more heat from the sun on the earth's surface). The post-IPCC AR4 sea level rise projections for Indonesian waters are also summarised in Table 2. These Post-IPCC AR4 sea level rise values are more than double the IPCC AR4 values for each projected year.
Table 2. Sea level rise projections for Indonesian waters relative to the level in 2000

\begin{tabular}{lll}
\hline $\begin{array}{l}\text { Projected } \\
\text { Year }\end{array}$ & IPCC AR4 & Post-IPCC AR4 \\
\hline 2030 & $22.5 \mathrm{~cm} \pm 1.5 \mathrm{~cm}$ & $52.5 \mathrm{~cm} \pm 0.3 \mathrm{~cm}$ \\
2050 & $37.5 \mathrm{~cm} \pm 2.5 \mathrm{~cm}$ & $87.5 \mathrm{~cm} \pm 0.5 \mathrm{~cm}$ \\
2080 & $60 \mathrm{~cm} \pm 4 \mathrm{~cm}$ & $140 \mathrm{~cm} \pm 0.8 \mathrm{~cm}$ \\
2100 & $75 \mathrm{~cm} \pm 5 \mathrm{~cm}$ & $175 \mathrm{~cm} \pm 1 \mathrm{~cm}$
\end{tabular}

\subsection{Land-use change}

The difference in land use from 1996 to 2015 was compared for the most common SWAT land-use types in the region, the land use options include urban areas, forest areas, rice crop areas, etc. This helps decisionmakers and interested stakeholders visualize and understand the patterns in land-use changes to better plan adaptation measures. An example use case was to analyse the change in the "Urban" land-use type for the region between the years 1996-2015, urban areas have increased over the years. These layers are useful for identifying trends in changing land use for the region and climate change factors such as temperature and precipitation and in considering adaptations for expanding regions. As an example, by looking at areas where rice cropland is increasing, the relevant authorities can decide if the areas are suitable for the future by looking at projected temperature and precipitation data.

\section{EXAMPLE USE CASES FROM THE PLATFORM}

A few practical use cases from the platform are presented in this section of the paper. These cases include combinations of various datasets and provide an overview of how the data can be analysed to support urban planners and other stakeholders in decision making.

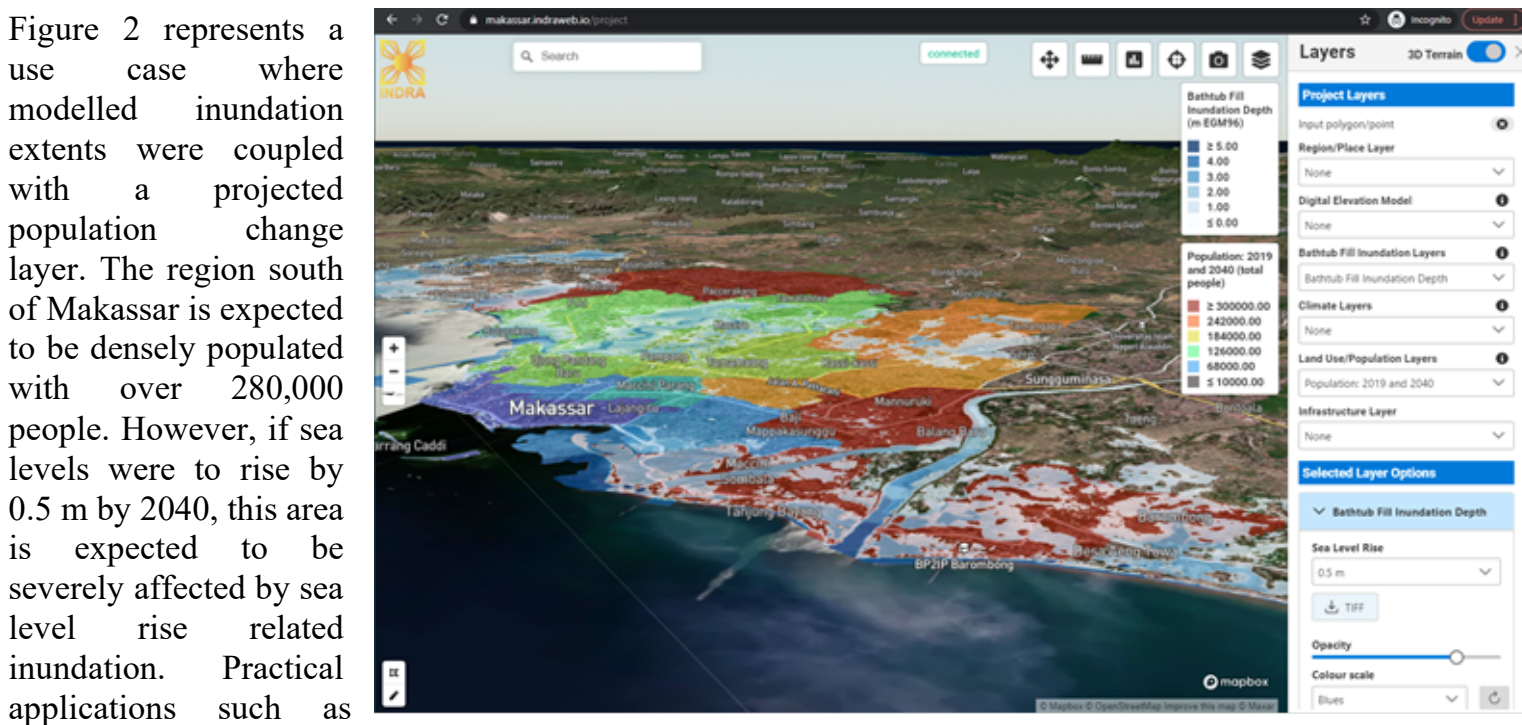
applications such as these will help Figure 2. Expected population in 2040 with inundated areas for a sea level rise governments and scenario of $0.5 \mathrm{~m}$ decision-makers to understand communities under risk ahead of time and plan new settlements accordingly whilst avoiding expanding into high-risk areas. A similar use case was to view an infrastructure layer with an inundation layer to assess the risks to an infrastructure feature. 
In Figure 3, the projected maximum temperature layer is enabled along with the expected population change from 2019 to 2040. The combination of the layers can help planners identify locations where temperatures are projected to increase to extreme levels. Using the point sampling tool, for the selected region where the mouse is hovering over, a projected maximum temperature of $32.23^{\circ} \mathrm{C}$ can be expected while a population increase of 75,437 people is projected by 2040 .

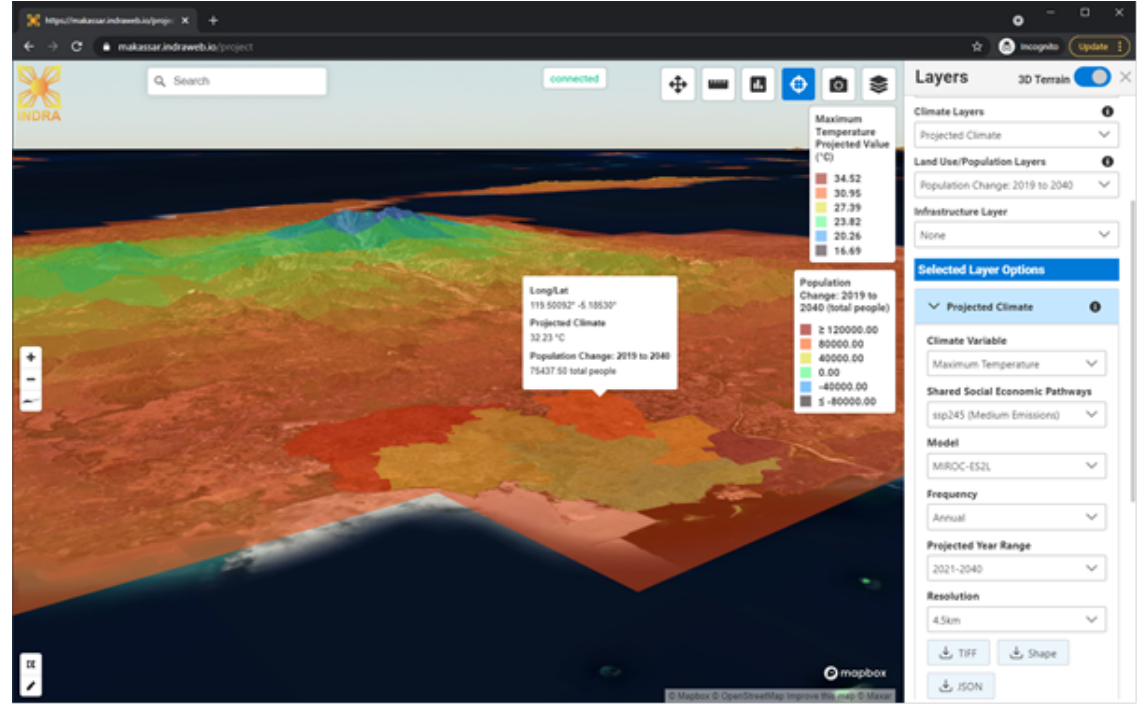

Figure 3. Projected maximum temperature with expected population change by 2040

\section{CONCLUSIONS}

INDRA Makassar was a digital climate resilience platform launched by CSIRO Data61 with inputs from Ramboll and the University of Hasanuddin as a part of the ASEAN Australia Smart Cities Trust Fund (AASCTF) funded by the Asian Development Bank (ADB). The platform was created for supporting the city of Makassar in South Sulawesi, Indonesia in implementing its liveable city plan and to make the city more resilient to climate change. The platform has made climate data easily accessible to interested parties whilst integrating various infrastructure, regional and demographic datasets to help planners understand the vulnerability of the city to climate change. The climate layers such as sea-level rise inundation depths, projected temperature and projected precipitation data will help urban planners to future-proof the city.

\section{ACKNOWLEDGEMENTS}

ADB and Ramboll Pty Ltd are greatly acknowledged for their support in the development of the INDRA Makassar Climate Resilience Platform. Additionally, Robert Power and Bella Robinson from CSIRO Data61 are acknowledged for their contribution in web deployment and frontend development.

\section{REFERENCES}

Alisjahbana A.S., Triastuti U.H., Tedjakusuma E.E., Mintzer I., Thamrin S., von Luepke H., Brulez B., 2010. Indonesia Climate Change Sectoral Roadmap - ICCSR. Scientific basis: Analysis and Projection of Sea Level Rise and Extreme Weather Events. https://www.bappenas.go.id/files/2013/5229/9917/analysis-andprojection-of-sea-level-rise-and-extreme-weathe_20110217130224_1.pdf

Eyring V., Bony S., Meehl GA., Senior C.A., Stevens B., Stouffer R.J., and Taylor K.E., 2016. Overview of the Coupled Model Intercomparison Project Phase 6 (CMIP6). experimental design and organization, Geoscientific Model Development, 9, 1937-1958 https://doi.org/10.5194/gmd-9-1937-2016

Fick S.E. and Hijmans R.J., 2017. WorldClim 2: new $1 \mathrm{~km}$ spatial resolution climate surfaces for global land areas. International Journal of Climatology 37 (12): $4302-4315$.

Geospatial Information Agency Indonesia, 2018. Seamless Digital Elevation Model (DEM) and National Bathymetry (DEMNAS). Viewed 15 April 2021, https://tanahair.indonesia.go.id/demnas/\#/

Hausfather Z., 2019. Explainer: The high-emissions 'RCP8.5' global warming scenario. Viewed 2 April 2021, https:/www.carbonbrief.org/explainer-the-high-emissions-rcp8-5-global-warming-scenario

Heliani L.S., Ateya I.L., Fukuda Y., Takemoto S., 2002. Mean Sea Level and Sea Surface Variability of Indonesian Waters from Topex/Poseidon. In: Drewes H., Dodson A.H., Fortes L.P.S., Sánchez L., Sandoval P. (eds) Vertical Reference Systems. International Association of Geodesy Symposia, vol 124. Springer, Berlin, Heidelberg. https://doi.org/10.1007/978-3-662-04683-8_49

Texas A\&M University (2012) SWAT Input/Output File Documentation, Version 2012, 564-575. Viewed 30 April 2021, https://swat.tamu.edu/media/69419/Appendix-A.pdf 